\title{
Intravenous Chemotherapy Adherence of Cancer Patients in Time of Covid-19 Crisis
}

\author{
Ismail BEYPINAR, Muslih URUN \\ Eskisehir City Hospital, Department of Medical Oncology, Eskisehir, TURKEY
}

\begin{abstract}
SARS-CoV-2 is a single-stranded RNA spherical virus spikes formed by glycoproteins. The leading cause of death was linked to acute respiratory distress syndrome, myocardial injury, or renal failure. After the first case reported on the 11th of March in Turkey Ministry of Health and Interior declared some regulations on the public, such as travel restrictions, traffic restrictions, social distancing homes, and centralized quarantine. Although chemotherapy adherence is a highly studied area for both oral and intravenous agents in cancer patients, no available data exist in a pandemic world with many social restrictions. The records of patients who have active cancer treatment in the department of medical oncology retrospectively analyzed. The age, gender, diagnosis, chemotherapy type, rendezvous, and coming dates recorded. Four chemotherapy delays (3.7\%) were observed out of 52 patients before the 11 th of March 2020, while 43 chemotherapy delays (39,8\%9) occurred out of 107 patients after the first COVID-19 case and the restrictions in Turkey. Twenty patients had treatment delay without reason and did not show up for treatment on the day of chemotherapy. The treatment delays without reasons are significantly different in the pre and post COVID-19 pandemic era. The hematologic toxicity rates were similar when compared pre and post COVID-19 period. The non-specific regulations and declarations confuse the patients and prevent them from reaching the treatment which is needed. In the case of pandemic regulations, oncologic patients may have special considerations for government decisions.
\end{abstract}

Keywords: COVID-19, SARS-COV-2, Cancer, Chemotherapy, Adherence

\section{INTRODUCTION}

SARS-CoV-2 is a single-stranded RNA spherical virus spikes formed by glycoproteins. ${ }^{1}$ There are seven subtypes of the coronaviruses infecting humans, including MERS, SARS-CoV-1, and SARSCoV-2 (COVID-19). ${ }^{2}$ COVID-19 targets ciliated bronchial epitheliums and alveolus via angiotensin-converting-enzyme 2 (ACE-2). The primary transmission way of the virus is air-borne droplets. ${ }^{3,4}$ The most reported symptoms were fever, cough, and shortness of breath. The leading cause of death was linked to acute respiratory distress syndrome, myocardial injury or renal failure. ${ }^{5}$

After the COVID-19 outbreak, which started in China in the last month of 2019, accumulating evi- dence supported the highly effected groups were older and immunocompromised patients. The high frequency of fatal respiratory disease was the major problem during the treatment of COVID-19. ${ }^{6} \mathrm{~Pa}-$ tients who undergo cancer or transplant treatment considered to be under increased risk. The risk for the infection in pandemic mainly derived from immunosuppressive and immunostimulant drugs. ${ }^{7,8}$ Although there are reports of cancer patients who received chemotherapy or tyrosine kinase inhibitors, no COVID-19 cases were reported immunecheckpoint inhibitors such as anti-CTLA-4 (Common T-lymphocyte antigen-4). ${ }^{9}$ Coronaviruses are the second leading cause of the viral infections after rhinoviruses in pediatric cancer patients who undergo chemotherapy. ${ }^{10}$ 
The prior cases associated with coronavirus before the outbreak were reported in a brain biopsy on one year child with acute B cell leukemia and a stage III breast cancer patient who had received high-dose chemotherapy and autologous stem-cell transplantation. ${ }^{11,12}$

World Health Organization had reported over two and half million confirmed cases, nearly two hundred thousand deaths till the 25th of April worldwide. ${ }^{13}$ Oncology organizations declared specific propositions for patient care for both adjuvant and palliative care..$^{14,15}$

After the first case reported on the 11th of March in Turkey Ministry of Health and Interior declared some regulations on the public, such as travel restrictions, traffic restrictions, social distancing homes, and centralized quarantine. ${ }^{16}$ In a recent study which based on case fatality rate estimation, authors reported that the outbreak in Turkey would resemble Europe countries, especially France. ${ }^{17}$

Although chemotherapy adherence is a highly studied area for both oral and intravenous agents in cancer patients, no available data exist in a pandemic world with multiple social restrictions..$^{18,19}$

In this study, we try to evaluate how hospital fear and social regulations affect the intravenous chemotherapy adherence of cancer patients.

\section{PATIENTS \& METHOD}

\section{Study Participants}

The records of patients who have active cancer treatment in the department of medical oncology retrospectively analyzed. The age, gender, diagnosis, chemotherapy type, rendezvous, and coming dates recorded. Also, the COVID-19 infection and the last status of the patients were registered. The delays of three consecutive chemotherapy before and after the 11th of March were enlisted. The patients who did not have adequate patient records were excluded from the study.

The study was approved by both the Turkish Ministry of Health and the ethics committee at Eskişehir Osmangazi University Faculty of Medicine and carried out by the Declaration of Helsinki principles and all applicable regulations.

\section{Statistics}

The statistical analysis of the study performed with SPSS version 22.0 software. Descriptive data are presented as either means or median for continuous variables, frequencies and percentages are reported for categorical variables. Pearson $\mathrm{X}^{2}$ test is used to assessing the associations in categorical variables. The rates compared with Z-test by E-PICOS software.

\section{RESULTS}

One hundred eight patients enrolled in the study. The age of the participants changed between 22 and 83 , with a mean value of 58 years. The study population had a female predominance, and frequencies of female and male patients were 67 and 41 , respectively. Most of the patients had breast cancer with $43.5 \%$, following colorectal cancer

\begin{tabular}{|c|c|c|c|c|}
\hline \multicolumn{5}{|l|}{ Features } \\
\hline Gender & Male & & Female & \\
\hline$n:(\%)$ & 41 (38\%) & & 67 (62\%) & \\
\hline Age & Mean & & Median & \\
\hline Years & 58,02 & & 58 & \\
\hline COVID Testing & Positive & Negative & Not Performed & \\
\hline n: (\%) & $0(0)$ & $40(37,3)$ & $67(63,3)$ & \\
\hline Diagnosis & Breast & Colorectal & Lung & Other \\
\hline $\mathrm{n}:(\%)$ & $47(43,5)$ & $26(22,2)$ & $14(14)$ & $23(21,3)$ \\
\hline Stage & 1 & $\|$ & III & IV \\
\hline n: (\%) & $3(2,8)$ & $25(23,1)$ & $41(38)$ & $39(36,1)$ \\
\hline Treatment Type & Adjuvant & & Palliative & \\
\hline n: (\%) & $69(63,9)$ & & $39(36,1)$ & \\
\hline
\end{tabular}




\begin{tabular}{|c|c|c|c|}
\hline \multicolumn{4}{|l|}{ Features } \\
\hline Treatment delay (All population) & Pre-COVID-19 & Post-COVID-19 & $p$ value \\
\hline$n:(\%)$ & $4 / 52(3.7)$ & 43/107 (39.8) & $<0.001$ \\
\hline Treatment delay (Adjuvant treatment) & Pre-COVID-19 & Post-COVID-19 & p value \\
\hline$n:(\%)$ & $3 / 31(9.7)$ & 28/69 (40.6) & 0.002 \\
\hline Treatment delay (Palliative treatment) & Pre-COVID-19 & Post-COVID-19 & $p$ value \\
\hline$n:(\%)$ & $1 / 21(4.8)$ & 15/38 (39.4) & 0.004 \\
\hline Treatment delay (Breast Cancer) & Pre-COVID-19 & Post-COVID-19 & $p$ value \\
\hline$n:(\%)$ & $1 / 24(4)$ & $13 / 47$ (27.6) & 0.01 \\
\hline Treatment delay (Breast Cancer) & Pre-COVID-19 & Post-COVID-19 & $p$ value \\
\hline$n:(\%)$ & $0 / 8(0)$ & $6 / 13(46.3)$ & 0.02 \\
\hline Treatment delay (Colon Cancer) & Pre-COVID-19 & Post-COVID-19 & $p$ value \\
\hline$n:(\%)$ & $1 / 13(7.6)$ & $12 / 24(50)$ & 0.01 \\
\hline Treatment delay (Other Cancers) & Pre-COVID-19 & Post-COVID-19 & p value \\
\hline$n:(\%)$ & $2 / 7(28)$ & $11 / 23(47)$ & 0.36 \\
\hline Treatment delay (Per Person in Pre-COVID-19) & 1st Cycle & 2nd Cycle & 3rd Cycle \\
\hline Days (Range) & $0.11(0-3)$ & $0.16(0-6)$ & $0.18(0-3)$ \\
\hline Treatment delay (Per Person in Post-COVID-19) & 1st Cycle & 2nd Cycle & 3rd Cycle \\
\hline Days (Range) & $1.89(0-77)$ & $1.09(0-26)$ & $2.05(0-75)$ \\
\hline
\end{tabular}

with $24.1 \%$. Two-thirds of the chemotherapies were adjuvant treatment, while one third was used for palliative intent (Table 1).

Four chemotherapy delays (3.7\%) were observed out of 52 patients before the 11th of March 2020, while 43 chemotherapy delays (39.8\%9) occurred out of 107 patients after the first COVID-19 case and the restrictions in Turkey $(\mathrm{p}<0.001)$. The significant difference between groups remained after the exclusion of the patients who had died during treatment $(\mathrm{p}<0.001)$. In terms of adjuvant treatment, the delays or discontinuations were significantly different among pre and post COVID-19 era $(p=0.002)$. The mean days of delay rates for three cycles before the COVID-19 cases were 0.11 , $0.16,0.18$ days per patient, respectively. After the COVID-19 cases and regulations, the mean delay of the three chemotherapy cycles was $1.89,1.09$, and 2.05 days per patient, respectively (Table 2 ).

No hospitalization resulted in treatment discontinuation or delay was observed in the study population. The reasons for treatment delays investigated in three groups before and after the COVID-19 pandemic. The groups established for hematologic toxicity, no reasons, and other (imaging, COVID-19 investigation, infections, or death). In the pre-pandemic period, two out of four patients had hematologic toxicity resulted in treatment delay. One patient had infection, while other had imaging for symptoms. No patient had treatment delay without reason in the pre-COVID-19 pandemic. In the pandemic period, nine patients had hematologic toxicity resulted in a treatment delay. Two patients had died, reasons which are related to cancer. No COVID-19 infection and related death observed in the study population. Forty patients tested for COVID-19 in the study population during treatment with nasopharyngeal swabs and no infections detected. Two patients had additional imagining studies. The rest of the patients had treatment delay due to other reasons. Twenty patients had treatment delay without reason and did not show up for treatment on the day of chemotherapy. The treatment delays without reasons are significantly different in the pre and post COVID-19 pandemic era. ( $\mathrm{p}=$ $0.05)$ The hematologic toxicity rates were similar when compared pre and post COVID-19 period. $(\mathrm{p}=0.24)($ Table 3$)$. 
Table 3. The comparison of the reasons resulted in treatment delays

\begin{tabular}{llll}
\hline Group & Pre-CovID-19 & Post-CovID-19 & p-value \\
Hematologic Toxicity n (\%) & $2 / 4(50 \%)$ & $9 / 39(23.1 \%)$ & 0.24 \\
No Reasons & $0 / 4(0 \%)$ & $20 / 39(51.3 \%)$ & 0.05 \\
Other (imaging, infections, COVID-19 investigation, death) & $2 / 4(50 \%)$ & $11 / 39(28.2 \%)$ & 0.36
\end{tabular}

* One patient had two treatment delays

\section{DISCUSSION}

In this study, we found the COVID-19 pandemic and the social regulations harmed intravenous chemotherapy adherence of the patients. Although chemotherapy adherence highly investigated area, there is no literature for intravenous chemotherapy adherence in the pandemic.

There is heterogeneity in cancer treatment across derived organs and histologic subtypes, which made the recommendations unique for the disease type. Dietz et al. ${ }^{20}$ declared three major groups in breast cancer treatment. Group A considered having an urgent need for treatment, and group $\mathrm{C}$ might be delayed. Group B was positioned between these groups. The (neo)adjuvant treatments, anti-HER-2 agents and maintenance treatments such as TDM1 and capecitabine were determined in group A, while bone modifying agents, bone densitometry and echocardiographic evaluations were considered to be group C. The immunotherapeutic agents, CDK4/6 and M-Tor inhibitors were needed to be decided case by case in terms of benefit/harm ratio. ${ }^{20}$ In our study, we found a significant disruption in intravenous chemotherapy adherence, but the bone modifying agents or other supportive treatment options was not evaluated.

European Society of Medical Oncology had recommendations on colorectal cancer patients. In patients with stage 2 disease, MSI testing must be performed for treatment decisions. The patient who is planning to treated with capecitabine, dihydro pyrimidine dehydrogenase test must be considered. Capecitabine treatment must be preferred among infusional 5-FU. Patients must be regarded as according to the IDEA trial, and if appropriate, three months duration of therapy must be chosen. Tele-medicine must be applied to proper patients to avoid unnecessary hospital visits. Granulocyte colony-stimulating factors must be used in high risk or recurrent neutropenic patients to avoid hospitalization. American Society of Clinical Oncology made nearly the same recommendations, adding to consider treatment in non-curative intent for risk/ benefit ration case by case..$^{21}$ Telemedicine or other long-distance communication methods are not highly available between patients and physicians in Turkey. Loss of adherence to chemotherapy may also be related to these circumstances.

The most cancer type which is detected on COVID-19 infection is lung cancer. Lung cancer is consisting of nearly one-third of the whole patient population. ${ }^{22,23}$ In terms of COVID-19 pandemic, the curative treatment for lung cancer such as surgery or adjuvant chemotherapies are not suggested to be delayed. Also, the delay in palliative treatments for metastatic settings may result in a decrease in performance status, which may cause loss of treatment chance. Also, the postponement of palliation may increase the hospitalization and loss of valuable hospital capacity for the treatment of COVID-19 patients. ${ }^{24}$ Although the results of the treatment delay in lung cancer in our study, a significant loss of intravenous chemotherapy adherence was observed due to the COVID-19 pandemic.

The Turkish oncologic authorities declared to evaluate every chemotherapy receiving patient independently for possible risk-benefit acquisition but not offer to delay treatment for any cost. ${ }^{25}$ In a recent study, Guven et al. reported a significant decrease in out-patient admissions after the first COVID-19 patients in a unique oncology center. Although they found a considerable difference for out-patient, they also reported a significant in- 
crease in hospitalization of patients for chemotherapy. The chemotherapy adherence of the patients was not reported. ${ }^{26}$

We believe, the disruption of chemotherapy adherence is derived from both social regulations and hospital fear. Also, some patients delayed their chemotherapies for the investigation of the COVID-19 infection. There was no COVID-19 infection in the study population and related death. There is an increased awareness in oncologic patients in Turkey, which may result in treatment delay, but also this phenomenon occurred in decreased COVID-19 infection and related death. The decrease of patients for medical advice also support this hypothesis. ${ }^{26}$

The hematologic toxicities were similar between the two periods, which may result in chemotherapy delay. The difference pattern on the treatment delays before and after COVID-19 cases in Turkey proved that a very high number of patients stopped their treatment without any reason. Although we evaluated the chemotherapy adherence of the patients, it's still unclear that the lack of adherence to the treatment will cause a decrease in survival or time without diseases. It's likely to have a reduction in cancer-related survival in the COVID-19 pandemic. However, some patients may not have adequate diagnostic procedures during this period. The regulations to prevent the worsening of the COVID-19 pandemic may harm specific patient populations such as chemotherapy receiving patients. The non-specific rules and declarations confuse the patients and prevent them from reaching the treatment which is needed. In the case of pandemic regulations, oncologic patients may have special considerations for government decisions.

Limitations: The study had a retrospective design that made data quality low. Although the complications or other hospital interventions were recorded, some social factors were not known, which might cause delays in chemotherapy rendezvous but considered to be equal for both pre and post COVID-19 periods. Also, the delay reason was not evaluated; both may depend on restrictions, hospital fear, or other purposes. The difference treatment counts between pre and post-COVID-19 period is related to the new establishment of the cancer center.

\section{Conclusion}

Social regulations and hospital fear had significantly resulted in treatment delays. Special attention must be paid for the unique patient population before having decisions for social rules. More studies are needed to prove the effectiveness of the COVID-19 pandemic on oncologic patients' population.

\section{Acknowledgment}

Special thanks to Hasan Karabulut for the help in data collection.

\section{REFERENCES}

1. Wassenaar TM, Zou Y. 2019_nCoV/SARS-CoV-2: rapid classification of betacoronaviruses and identification of Traditional Chinese Medicine as potential origin of zoonotic coronaviruses. Lett Appl Microbiol 70: 342-348, 2020.

2. Gorbalenya A, Baker S, Baric R, et al. Severe acute respiratory syndrome-related coronavirus: The species and its viruses - a statement of the Coronavirus Study Group. Nat Microbiol [Internet] 2020;2020.02.07.937862. Available from: http:// biorxiv.org/content/early/2020/02/11/2020.02.07.937862. abstract

3. Benvenuto D, Giovanetti M, Ciccozzi A, et al. The 2019-new coronavirus epidemic: Evidence for virus evolution. J Med Virol 92: 455-459, 2020.

4. Lu R, Zhao X, Li J, et al. Genomic characterisation and epidemiology of 2019 novel coronavirus: implications for virus origins and receptor binding. Lancet 395: 565-574, 2020.

5. Jiang $F$, Deng $L$, Zhang $L$, et al. Review of the clinical characteristics of Coronavirus disease 2019 (COVID-19). J Gen Intern Med 35: 1545-1549, 2020.

6. Chen N, Zhou M, Dong X, et al. Epidemiological and clinical characteristics of 99 cases of 2019 novel coronavirus pneumonia in Wuhan, China: a descriptive study. Lancet 395: 507-513, 2020.

7. Xia Y, Jin R, Zhao J, et al. Risk of COVID-19 for patients with cancer. Lancet Oncol 21(4): e180, 2020.

8. Wang $\mathrm{H}$, Zhang L. Risk of COVID-19 for patients with cancer. Lancet Oncol 21(4): e181, 2020.

9. Russell B, Moss C, George G, et al. Associations between immune-suppressive and stimulating drugs and novel COVID-19 - A systematic review of current evidence. Ecancermedicalscience 14: 1022, 2020.

10. Benites ECA, Cabrini DP, Silva ACB, et al. Acute respiratory viral infections in pediatric cancer patients undergoing chemotherapy. J Pediatr (Rio J) 90: 370-376, 2014. 
11. Nilsson A, Edner N, Albert J, Ternhag A. Fatal encephalitis associated with coronavirus OC43 in an immunocompromised child. Infect Dis (Auckl) 52: 419-422, 2020.

12. Folz RJ, Elkordy MA. Coronavirus pneumonia following autologous bone marrow transplantation for breast cancer. Chest 115: 901-905, 1999.

13. Livingston E, Bucher K, Rekito A. Coronavirus disease 2019 and Influenza 2019-2020 [Internet]. JAMA - J Am Med Assoc 323: 1122, 2020.

14. Thomson DJ, Palma D, Guckenberger M, et al. Practice recommendations for risk-adapted head and neck cancer Radiation therapy during the COVID-19 Pandemic: An ASTROESTRO Consensus Statement. Int J Radiat Oncol Biol Phys 107: 618-627, 2020.

15. Mohile NA, Blakeley JO, Gatson NTN, et al. Urgent considerations for the neuro-oncologic treatment of patients with gliomas during the COVID-19 pandemic. Neuro Oncol 22: 912-917, 2020.

16. 30-buyuksehir-ve-zonguldak-ilinde-23-24-25-26-nisan-tarinlerinde-uygulanacak-sokaga-cikma-kisitlamasi [Internet]. Available from: https://www.icisleri.gov.tr/30-buyuksehir-vezonguldak-ilinde-23-24-25-26-nisan-tarihlerinde-uygulanacak-sokaga-cikma-kisitlamasi

17. Javed A. Case fatality rate estimation of COVID-19 for European countries: Turkey's current scenario amidst a global pandemic; Comparison of outbreakswith European Countries. Eurasian J Med Oncol 4: 149-159, 2020.

18. Greer JA, Pirl WF, Park ER, et al. Behavioral and psychological predictors of chemotherapy adherence in patients with advanced non-small cell lung cancer. J Psychosom Res 65: 549-552, 2008.

19. Jacobs JM, Ream ME, Pensak N, et al. Patient experiences with oral chemotherapy: Adherence, symptoms, and quality of life. JNCCN- J Natl Compr Cancer Netw 17: 221-228, 2019.

20. Dietz JR, Moran MS, Isakoff SJ, et al. Recommendations for prioritization, treatment, and triage of breast cancer patients during the COVID-19 pandemic. the COVID-19 pandemic breast cancer consortium. Breast Cancer Res Treat 181: 487-497, 2020.
21. Lou E, Beg S, Bergsland E, et al. Modifying practices in Gl oncology in the face of COVID-19: Recommendations from expert oncologists on minimizing patient risk. JCO Oncol Pract 16: 383-388, 2020.

22. Liang W, Guan W, Chen R, et al. Cancer patients in SARSCoV-2 infection: a nationwide analysis in China. Lancet Oncol 21: 335-337, 2020.

23. Zhang L, Zhu F, Xie L, et al. Clinical characteristics of COVID19-infected cancer patients: a retrospective case study in three hospitals within Wuhan, China. Ann Oncol 31: 894-901, 2020.

24. Ueda M, Martins R, Hendrie PC, et al. Managing cancer care during the COVID-19 Pandemic: Agility and collaboration toward a common goal. J Natl Compr Canc Netw 18: 1-4, 2020.

25. Sumbul AT, Yalcin S, Ozet A, et al. Turkish Medical Oncology Society COVID-19 pandemic advisory board recommendations for cancer patients and medical oncologist. J Oncol Sci 6: 1-4, 2020.

26. Guven DC, Aktas BY, Aksun MS, et al. COVID-19 pandemic: changes in cancer admissions. BMJ Support Palliat Care 2020;bmjspcare-2020-002468 (on-line).

\section{Correspondence: \\ Dr. Ismail BEYPINAR}

Eskisehir Sehir Hastanesi

71 Evler Mahallesi Çevre Yolu

Çavdarlar Sokak

Tibbi Onkoloji Poliklinigi

26080 Odunpazari

ESKISEHIR / TURKEY

Tel: (+90-531) 9951906

e-mail: ibeypinar@yahoo.com

\section{ORCIDs:}

Ismail Beypinar

0000-0002-0853-4096

Muslih Urun 